\title{
O DIREITO EDUCACIONAL E A MUNICIPALIZAÇÃO DO ENSINO FUNDAMENTAL REGULAR: PRESSUPOSTOS, CONDIÇÕES E VANTAGENS
}

Vicente de Paula Silveira

ISSUE DOI: $10.21207 / 1983.4225 .289$

\section{RESUMO}

Trata-se de um tema de alta relevância no Direito Educacional contemporâneo, que problematiza um elenco significativo de pressupostos, condições e vantagens, objetivando estudar a questão da municipalização do ensino fundamental regular em seus aspectos jurídico-pedagógicos e institucionais, contribuindo para o enriquecimento do campo teórico do Direito Educacional, para a construção e/ou reconstrução de sistemas de ensino municipais eficientes, através da análise crítica de seus elementos normativos, institucionais e financeiros, bem como fornecendo subsídios aos dirigentes municipais de educação para implementação e gerenciamento do processo de municipalização do ensino, de forma democrática, competente, transparente e participativa. Pelos estudos e análises realizadas, concluiu-se pela oportunidade, conveniência, necessidade e viabilidade do processo de municipalização do ensino fundamental, desde que realizado 
por homens compromissados com a qualidade da educação pública e imbuídos de uma vontade política de realizá-la.

Palavras-chave: Direito educacional. Municipalização. Pressupostos. Condições. Vantagens.

\section{INTRODUÇÃO}

Os estudiosos do Direito Educacional apontam como características marcantes atuais da educação pública brasileira, em especial, do ensino público fundamental, a descentralização (política, administrativa, pedagógica, financeira, etc.), a participação, a autonomia e as parcerias na gestão pública educacional.

Do ponto de vista epistemológico, a educação e o Direito mantêm relações íntimas, a começar pelo fato de a educação preceder o Direito na formação dos seres humanos e de todos os operadores do Direito Educacional passarem por um processo formal nos cursos jurídicos, que funcionam no seio dos sistemas de ensino.

O Direito, por vincular pretensões de uns com deveres de outros ou por atribuir competência ou poder para praticar certos atos e a outros, dever de respeitá-los, caracteriza-se pela bilateralidade das normas e pela sanção do poder público, no dizer de Paulo Dourado de Gusmão. ${ }^{207}$ Conseqüientemente, uma das evidências dessa bilateralidade reside em que não pode alguém inibir o desenvolvimento de outrem; ao contrário, em relação ao sujeito do direito de crescer, todos os outros se põem na posição de polo passivo da relação jurídica, como consagra o art. 205 citado, litteris: "A educação, direito de todos e dever do Estado e da família, será promovida e incentivada com a colaboração da sociedade, visando ao pleno desenvolvimento da pessoa, seu preparo para o exercício da cidadania e sua qualificação para o trabalho".

Encontramos também na norma constitucional acima descrita, as demais características da norma jurídica formal, representadas pela generalização e pela coercitividade ou imperatividade. A generalidade se percebe quando a Constituição consagra a educação como direito de todos, tendo como contrapartida o dever do Estado, da família e da sociedade. A

${ }^{207}$ GUSMÃO, Paulo Dourado de. Introdução ao Estudo do Direito. 39. ed. Rio de Janeiro: Forense, 2007. p. 50. 
coercibilidade ou imperatividade própria de norma cogente transparece quando se observa a presença de direitos e obrigações com suas correspondentes sanções. A própria norma constitucional expressa no $\S 1^{\circ}$ do art. 208 da atual Constituição, confirma o ordenamento coercível do Direito Educacional, quando eleva à condição de direito público subjetivo o acesso ao ensino fundamental regular, obrigatório e gratuito, com duração de 9(nove) anos, iniciando-se aos 6(seis) anos de idade, conforme determina a Lei $n^{\circ} 11.274$, de 06/02/2006, que alterou a LDB.

A sistematização do Direito Educacional se processou com o atendimento aos critérios de ordem técnico-jurídica contidos nas seguintes exigências básicas:

a) norma jurídica formal, dotada de bilateralidade, imperatividade, generalidade, impessoalidade, permanência, constitucionalidade e coercitividade;

b) validade, compreendendo a vigência, a eficácia e o fundamento axiológico (justiça);

c) fontes formais e materiais de onde promana o novo ramo jurídico (Direito Educacional).

Torna-se, pois, induvidosa a concepção e definição do novo ramo integrante da ciência jurídica, dotado de objeto e método próprios.

Quanto às conceituações oferecidas pela literatura jurídica consultada, cumpre destacar as dos seguintes autores:

a) Alberto Teodoro Di Dio: "Conjunto de normas, princípios, leis e regulamentos que versam sobre as relações de alunos, professores, administradores, especialistas e técnicos, enquanto envolvidos mediata e imediatamente no processo ensino/aprendizagem". ${ }^{208}$

b) Pedro Sancho da Silva: "Ramo do Direito Social constituído de um conjunto de princípios e normas que presidem às relações jurídicas decorrentes do processo educacional, ou ainda que se trata de uma disciplina jurídica informadora das relações de direito e deveres ocorrentes na Educação como processo pedagógico e como direito subjetivo público" 209;

${ }^{208}$ DI DIO, Roberto Teodoro. Contribuição à Sistematização do Direito Educacional. Taubaté: Imprensa Universitária/Universidade de Taubaté, 1982.

${ }^{209}$ SILVA, Pedro Sancho da. Sistematização do Direito Educacional. Revista do Direito Educacional. Rio de Janeiro, Ano 9, n.46, set./out., 1997. p.25-46. 
c) José Augusto Peres: "Direito Educacional (...) é um ramo especial do Direito; compreende um já alentado conjunto de normas de diferente hierarquia; diz respeito bem proximamente ao Estado, ao educador e ao educando; lida com o fato educacional e com os demais fatos a ele relacionados; rege as atividades no campo do ensino e/ou aprendizagem de particulares e no poder público, de pessoas físicas e jurídicas, de entidades públicas e privadas". ${ }^{210}$

Pelo exposto, depreende-se facilmente que o Direito Educacional deixou de ser um conjunto de "normas programáticas", desprovidas de coercitividade, dotadas apenas de simples "intenções", não se reduzindo tampouco, nas limitadas concepções de "legislação escolar" ou "legislação de ensino", mas conseguiu a necessária sistematização através de um procedimento técnico-jurídico pelo qual todas as normas relativas ao direito à educação se contêm com absoluta propriedade, em um sistema jurídico capaz de assegurar a todos, direitos, exigindo da outra parte o cumprimento dos deveres, consignando sanções por sua inobservância.

Em suma, o Direito Educacional apresenta plena afinidade com a cultuada e tradicional definição filosófica de Direito, exposta por Miguel Reale: "Direito é uma ordenação coercível, heterônoma, bilateralatributiva, da conduta humana, na medida do bem comum". ${ }^{211}$

O compromisso do poder público municipal com o ensino fundamental determinado constitucionalmente, aliado a um ordenamento normativo infraconstitucional, representado principalmente pela Nova Lei de Diretrizes e Bases da Educação Nacional (Lei Federal N.9.394/96) e pela Lei Federal N.9.424/96, que regulamentou o Fundo de Manutenção e Desenvolvimento do Ensino Fundamental e de Valorização do Magistério (FUNDEF), alterada pela Lei $n^{\circ} 11.494$, de 20/06/2007, que instituiu o FUNDEB e revogou os artigos $1^{\circ}$ a $8^{\circ}$ e 13 da Lei $n^{\circ} 9.424 / 2007$, acima citada, desencadeiam o início efetivo do processo de municipalização, acolhido também pelas normas emanadas dos governos estaduais e de seus órgãos normativos.

A análise acurada do referencial teórico de natureza bibliográfica e documental, complementada pela experiência variada do autor na área de educação pública e privada no Estado de São Paulo, demonstrou, além do reconhecimento inquestionável da municipalização do ensino

\footnotetext{
${ }^{210}$ Ibidem.

${ }^{211}$ Ibidem.
} 
fundamental regular paulista como realidade quase irreversível, a possível e desejada superação de seus obstáculos, de suas dificuldades e objeções.

A municipalização do ensino é um tema que consta da pauta dos debates que se travam na área das políticas públicas, capaz de gerar novas discussões e pesquisas, visto tratar-se de uma verdadeira mudança cultural, assentada em novos paradigmas, pois supõe a passagem de uma estrutura autoritária, verticalizada, hierarquizada, centralizada, eivada de vícios, para uma estrutura democrática, horizontalizada, descentralizada, flexível, participativa e autônoma, porém, articulada com os demais sistemas de ensino (nacional e estadual). Tal mudança estrutural não resulta necessariamente da simples municipalização do ensino fundamental, mas depende de uma série de pressupostos e condições elencados neste trabalho.

A contemporaneidade e importância dos atuais sistemas de ensino municipais que estão se formando gradativamente nos Estados brasileiros de forma irreversível, com a consequente diminuição da rede de escolas públicas estaduais de ensino fundamental regular, atestam de forma inequívoca a relevância tempestiva destes estudos, ainda mais considerando, que o povo mora no Município e nele tem sua escola, seu lar, sua profissão, sua propriedade, suas instituições, seus interesses e aspirações.

A educação fundamental regular é investimento indispensável para a construção de uma sociedade democrática, organizada, mobilizada, humana, justa, caracterizada pela cidadania e participação. Uma municipalização desejada, discutida e negociada, democrática e diagnosticada, gradual, progressiva e diferenciada, fundamentada numa ética antropológica de solidariedade, de compromisso leal com a educação pública de qualidade, é condição básica para o exercício consciente da cidadania, trazendo os problemas mais perto do povo para que este participe de suas soluções.

Espera-se alcançar com os resultados deste trabalho os seguintes objetivos:

a) estudar a questão da municipalização do ensino fundamental regular em seus aspectos jurídico-pedagógicos e institucionais, contribuindo para o enriquecimento do campo teórico do Direito Educacional;

b) contribuir para a construção e/ou reconstrução de sistemas de ensino municipais eficientes, através da análise crítica de seus elementos normativos, institucionais e financeiros; 
c) fornecer subsídios aos dirigentes municipais de educação para implementação e gerenciamento do processo de municipalização do ensino, de forma democrática, competente, transparente e participativa;

d) demonstrar aos trabalhadores em educação e demais interessados no tema, que a municipalização do ensino fundamental regular pode e deve se transformar numa proposta viável e renovadora, se conduzida dentro dos parâmetros, pressupostos e condições sugeridas.

\section{$1 \quad$ PRESSUPOSTOS}

Percorrendo todo o caminho jurídico-pedagógico proporcionado pelo Direito Educacional, dentro da temática que se abraçou, podem-se inferir alguns pressupostos, condições de viabilidade e vantagens do processo de municipalização do ensino fundamental regular.

A prevalência da abordagem normativa que norteou todo este trabalho assinala como pressuposto fundamental da municipalização a autonomia municipal, garantida pela ordem jurídica. A autonomia torna possível à autogestão e a adoção de soluções diferentes pelos diversos Municípios, na busca contínua da correção das desigualdades regionais e locais, com a devida conivência e articulação com os demais poderes públicos diferentes e também autônomos.

Só uma verdadeira e efetiva autonomia dá legitimidade à declaração de interesse do Município em municipalizar a educação fundamental e em responsabilizar-se por sua qualidade e universalidade, bem como em aplicar adequadamente os recursos repassados, necessários aos novos encargos e serviços transferidos.

A própria organização da educação nacional disciplinada pelo Direito Educacional contém indicadores explícitos apontados para uma educação local, significando que o lugar mais apropriado para a resolução dos problemas educacionais, no fundo, é o Município, que conta com a participação direta dos interessados (art.11 da LDB).

A municipalização, por ser um processo, deve ocorrer de forma gradativa, descentralizada e diferenciada, somente possível, se o Município atuar de forma autônoma, no âmbito didático, pedagógico, financeiro e administrativo. 
Uma autêntica reforma tributária que viabilize o equilíbrio de competências, atribuições, encargos e serviços, que evite o vaivém de recursos alocados no próprio Município com destinação específica para a educação, também são pressupostos relevantes para o processo de municipalização.

Uma lista de pressupostos complementares contemplaria ainda os seguintes:

a) assessoria técnica aos Municípios pelos Estados e União para o seu regular desempenho técnico-científico, principalmente no que se refere à manutenção da unidade pedagógica do ensino fundamental, preservando a base nacional comum e as especificidades regionais e locais nas experiências curriculares;

b) recursos de suportes, indispensáveis ao processo de municipalização, tais como: recursos humanos, financeiros, normativos, jurídicoinstitucionais (Planos de Educação, de Carreira, Regimento, órgãos colegiados, etc);

c) autonomia da escola, que para José Carlos Melchior ${ }^{212}$, no caso da escola pública, restringe-se a alguns aspectos da autonomia administrativa, referentes à administração de recursos materiais de pequena monta, já que a administração de recursos humanos extrapola sua competência; a autonomia pedagógica, pela liberdade de elaboração de sua proposta pedagógica e seu currículo e à autonomia didática, por sua competência na elaboração, controle, execução e avaliação de suas atividades de aprendizagem.

Ainda na esteira do pensamento desse autor, não há autonomia financeira, já que a elaboração do orçamento, sua execução e controle são regidos por normas legais e fiscalizados pelo Tribunal de Contas e Câmara de Vereadores. Na escola pública, também não há autonomia filosófica, uma vez que os fins e objetivos são estabelecidos pela sociedade e consagrados em lei, nem tampouco autonomia política, que seria elemento desagregador do sistema de ensino como um todo articulado, sendo viável apenas a participação das escolas na elaboração de uma política de educação ${ }^{213}$. Tais comentários justificam a afirmação de que os "progressivos graus de autonomia pedagógica, administrativa e de gestão financeira, observadas as normas gerais de direito financeiro público" (art. 15 da

\footnotetext{
212 Ibidem.

${ }^{213}$ Ibidem. p. 45-47.
} 
LDB), que a lei deve assegurar às escolas ainda estão longe de serem conseguidos na prática, porém, já se constata um certo avanço nos aspectos pedagógicos e administrativos.

Mesmo garantindo a existência efetiva da maioria desses pressupostos, convém levantar alguns riscos mais relevantes, no processo de municipalização, historicamente comprovados tais como:

a) a autonomia pode levar os exegetas dos textos educacionais a interpretações abusivas que fogem aos propósitos de uma verdadeira flexibilidade, coerente com o compromisso educativo;

b) a autonomia pode ser aproveitada ou servir de justificativa para a implementação de ações corporativas locais e classistas, defensivas e reativas, com prejuízos para a aprendizagem, devido à possível prevalência dos direitos dos docentes sobre os direitos dos alunos;

c) a autonomia pode facilitar ou viabilizar políticas públicas locais nefastas para o setor educacional, justificando indevidamente a falta de recursos financeiros ou sua utilização em proveito próprio ou com fins eleitorais e demais formas de corrupção divulgadas pela imprensa ${ }^{214}$;

d) a autonomia pode também desconsiderar o saudável equilíbrio entre as normas de validade nacional e as peculiaridades locais, bem como, implantar, de forma irresponsável, a política do "vale tudo".

Por outro lado, os perigos da autonomia de que gozam também os Estados e a União, são também extensivos a essas esferas de poder, com o agravante de menor controle e fiscalização por parte dos usuários e o envolvimento de um montante maior de recursos humanos e financeiros.

Outra questão de alta relevância para o processo de municipalização é a valorização do magistério, que não deve ser entendida apenas como aumento de vencimentos em função de tempo de serviço, como acontece em muitos planos de carreira do magistério público municipal. Não há dúvida de que a qualidade inclui necessariamente quantidade, mas compõe-se também de outros ingredientes, pois todo investimento na valorização do docente tem que implicar na melhoria das condições de aprendizagem dos alunos. Isto significa compromisso com a educação e com o sucesso do aluno. A experiência tem demonstrado que não há cor-

\footnotetext{
${ }^{214}$ CERCO a Prefeitos Corruptos. Jornal da Tarde (Editorial), São Paulo, 14 ago. 1998. p. 2. Este editorial destaca o uso desenfreado da máquina administrativa municipal, improbidade, tráfico de influência, manipulação de licitações, nepotismo, crime de responsabilidade, desvio de recursos públicos, concorrência fraudulenta, peculato.
} 
relação positiva entre valorização do magistério e melhoria da qualidade do processo de aprendizagem, quando se considera apenas o aspecto financeiro. As normas do Direito Educacional reconhecem que o padrão de qualidade depende de critérios diversos e passa necessariamente por avaliações periódicas. Nesse particular é necessária a ocorrência de uma mudança cultural que sinalize no sentido de acolhimento das avaliações externas de nossas instituições de ensino, como um mecanismo de retroinformação das condições de saúde pedagógica dos sistemas de ensino.

\section{CONDIÇÕES}

A concepção de municipalização, que emana das normas do Direito Educacional brasileiro para se concretizar efetivamente, depende, além dos pressupostos já enunciados, da existência de condições propícias.

Uma gama de condições de ordem jurídico-pedagógicas, representadas principalmente pelos mecanismos jurídico-institucionais básicos (Plano Nacional de Educação, Plano Estadual de Educação, Plano Municipal de Educação, Planos de Carreira, Regimento Escolar, Projeto Pedagógico) e pelos órgãos colegiados normativos fundamentais (Conselho Nacional de Educação, Conselho Estadual de Educação, Conselho Municipal de Educação, Conselhos de Acompanhamento, Controle Social, Comprovação e Fiscalização de Recursos, criados por legislação específica, em âmbito federal, estadual, distrital e municipal, conforme o disposto no art. 24 da Lei n ${ }^{\circ} 11.494$, de 20/06/2007, do FUNDEB), são fundamentais para a eficiência do processo de municipalização.

$\mathrm{O}$ funcionamento articulado dos planos, a presença de normas emanadas dos órgãos colegiados, garantidoras de uma gestão democrática e de um padrão de qualidade, capazes de corrigir distorções didáticopedagógicas dos textos legais, a existência de recursos financeiros das diferentes fontes institucionais adequados aos novos encargos e serviços assumidos pelos Municípios, a reestruturação dos órgãos municipais de educação (Secretaria da Educação, Departamento da Educação, Coordenadoria, etc), a constituição de um sistema de ensino próprio ou mesmo a composição com o Estado de um sistema único, a assistência técnica dos demais poderes (Estado e União), constituem condições essenciais para a municipalização do ensino fundamental. Tais condições, se bem operacio- 
nalizadas, podem viabilizar a passagem de uma estrutura autoritária, verticalizada, hierarquizada, centralizada, para uma nova estrutura mais democrática, horizontalizada, descentralizada e participativa.

Segundo o Ministério da Educação (MEC), o êxito de uma municipalização do ensino depende das seguintes condições:

a) garantia de um conteúdo mínimo para o ensino fundamental que assegure uma formação comum e o respeito aos valores culturais, artísticos e às diversidades regionais, garantindo ao mesmo tempo, uma base estrutural; tais garantias devem estar inseridas numa Política Nacional de Educação contemplada efetivamente pelo Plano Nacional de Educação ;

b) definição legal das competências e responsabilidades da União, dos Estados e dos Municípios, quer específicas, quer concorrentes;

c) respeito às características dos Municípios e diagnóstico de suas demandas e viabilidades, assegurando-lhes o detalhamento de ações em articulação com os respectivos Estados, competindo ao Ministério da Educação (MEC) traçar as linhas gerais da política educacional;

d) elaboração do Plano Municipal de Educação com a participação da comunidade, cabendo ao governo municipal assegurar condições para sua viabilidade e implementação;

e) assessoramento técnico da União e dos Estados aos Municípios em processo de municipalização do ensino pré-escolar e do ensino fundamental. ${ }^{215}$

Cumpre salientar que não basta, entretanto, assegurar a condicionalidade legal para o processo de municipalização. Esta é fundamental, mas por si só não provoca compulsoriamente a vontade política, o compromisso com a educação e com o educando, o fazer pedagógico, a mobilização e a articulação da sociedade civil e, lamentavelmente, não impede o patrimonialismo, o clientelismo, o nepotismo e outros comportamentos negativos de nosso passado histórico, presentes ainda.

\section{VANTAGENS}

${ }^{215}$ CARVAlHO, José Raimundo. A Constituição e o Plano Nacional de Educação. In: Conselho de Reitores das Universidades Brasileiras. Brasília, 1988. p. 59-60. 
Com referência às vantagens advindas do processo de municipalização do ensino fundamental regular, o Ministério da Educação, por meio de sua Secretaria de Ensino Básico, assim se manifestou: a municipalização garante maior racionalização de recursos; permite mecanismos de ação e solução mais rápidos; possibilita a desburocratização do sistema; assegura maior conhecimento por parte da administração municipal da realidade física, social, econômica e cultural do Município e facilita o acompanhamento e a avaliação de todas as atividades, permitindo assim ao Município assumir de forma gradual e progressiva a responsabilidade do ensino. ${ }^{216}$

A municipalização do ensino é também recomendada por diversos estudiosos do assunto, os quais tecem uma linha de argumentação semelhante, como se depreende da análise dos textos abaixo:

“A escola municipalizada estará mais próxima , colada ao poder local e com isto se teria melhores condições de equacionar os problemas, o prefeito e os vereadores estariam 'à mão' e a 'comunidade' (...) teria todas as condições de controlar a gestão política no que concerne à escola". E mais: descentralizandose a administração, colocando-se a escola de $1^{\circ}$ grau nas mãos do Município, as possibilidades de gestão democrática são ampliadas". ${ }^{217}$

Formosinho entende que a municipalização apresenta vantagens de ordem política e técnica. Politicamente, cabe à descentralização administrativa "entregar às comunidades locais a gestão dos seus interesses próprios, o que resulta num aprofundamento da democracia e impede a criação de um Estado administrativo onipresente e asfixiante". Como vantagem técnica, continua, "permite decisões mais adequadas às necessidades locais por serem tomadas por pessoas que melhor as conhecem e estão sintonizadas com a vontade das populações". ${ }^{218}$

\footnotetext{
${ }^{216}$ BRASIL. MEC - Secretário do Ensino Básico, 1998. p. 59.

${ }^{217}$ MÁXIMO, Antônio Carlos. A municipalização do ensino. Brasília: Ministério da Educação, INEP, Ano 2, nº 9, dez.1987. p. 7.

${ }^{218}$ FORMOSINHO, João. A regionalização do sistema de ensino. In: Cadernos Municipais. Braga. n.38-39, dez. 1986. p. 65.
} 
Complementando as vantagens da municipalização do ensino, deve-se acrescentar ainda:

a) aumento da rapidez e da probabilidade de melhor acerto nas decisões pela proximidade temporal e espacial com a origem dos problemas;

b) possibilidade de melhor diagnóstico da situação problemática, pelo aumento da viabilidade e da transparência;

c) garantia de melhor planejamento, execução, controle, avaliação e fiscalização das ações e metas propostas, como consequência da descentralização, participação, autonomia e envolvimento dos próprios usuários;

d) favorecimento da racionalidade do processo administrativo e pedagógico, pela sensível diminuição do tamanho da máquina administrativa, tornando-a mais ágil e eficiente;

e) possibilidade de economia de tempo na correção de desvios, nas retroinformações que realimentam os replanejamentos;

f) aumento da responsabilidade e motivação pelos resultados operacionais esperados;

g) economia de recursos financeiros, eliminando viagens, tramitação de processos, expedientes, correspondências e telefonemas com os órgãos centrais, possibilitando um reforço salarial ao pessoal técnico, administrativo e docente.

\section{CONCLUSÃO}

Pela análise acurada de todos os aspectos abordados no desenvolvimento deste trabalho, fundamentada nas normas vigentes do Direito Educacional, com ênfase nos mecanismos jurídico-institucionais básicos, nos órgãos colegiados normativos fundamentais, na pluralidade das fontes de recursos financeiros, nos pressupostos, condições e vantagens do processo de municipalização do ensino fundamental, emerge como premissa inquestionável o reconhecimento da municipalização do ensino como uma realidade quase irreversível, que se concretiza paulatinamente, face à adesão de um número significativo de Municípios a esse processo. 
Diante de uma realidade inexorável, a postura mais indicada para uma abordagem mais sistemática possível é a abertura para o debate de ideias, na busca de soluções viáveis.

Depreende-se também, com base na literatura jurídicopedagógica consultada, que a atual política educacional brasileira está acolhendo e implementando novas ações, tendo como parâmetros a autonomia, a descentralização, a participação, a articulação de poderes e os contratos de parcerias. Na trilha de tais caminhos, não há mais lugar para maniqueísmos, preconceitos teóricos, ações corporativas, defensivas e reativas, passionalismos, mas sim, ações propositivas que resgatem a tão almejada qualidade da educação pública fundamental, guardiã do Estado Democrático de Direito e objetivo comum de todos os cidadãos, em especial dos educadores.

Os Municípios brasileiros apresentam grande assimetria em termos de população, área geográfica, demanda escolar, capacidade tributária, proposta orçamentária, condições institucionais, etc., transformandoos em unidades político-administrativas heterogêneas, revestidas de características peculiares. Assim também ocorre com os Municípios paulistas. Esse caráter assimétrico requer soluções próprias para seus problemas, principalmente na área da educação pública, na qual a importação de modelos prontos e acabados tem se mostrado inoperante.

Por outro lado, não se recomenda, obviamente, uma municipalização intempestiva, imediatista, por decreto, irresponsável, compulsória, autoritária, impositiva e uniforme, pois, não se tem resposta única para uma pluralidade de situações diferenciadas.

Uma municipalização do ensino fundamental responsável exige um diagnóstico de cada situação e uma análise das circunstâncias em que a proposta é apresentada, devendo ocorrer de forma gradual, progressiva e diferenciada.

Este trabalho demonstrou de forma satisfatória os seus pressupostos, as suas condições e suas vantagens, não havendo, portanto, nenhuma razão para se fazer uma objeção gratuita a uma municipalização desejada, discutida e negociada, democrática e diagnosticada, comprometida com a qualidade e a universalidade do ensino fundamental público, gratuito e obrigatório.

Não se cogitou, em nenhum momento, da adoção da posição de dono da verdade, nem de oráculo de enunciados dogmáticos e infalíveis, mas se considerou a municipalização do ensino fundamental uma proposta 
renovadora e viável, que bem conduzida, poderá eliminar os vícios e as distorções da vida pública nacional, estadual e municipal e vencer as dificuldades e objeções levantadas, viabilizando o surgimento de uma nova cultura política.

Não se compactuou também com um “ nihilismo" político e jurídico-pedagógico, tampouco com o acolhimento da idéia ingênua de considerar a municipalização do ensino como um remédio político para a cura de todos os males da educação pública fundamental. Razão assiste a alguns estudiosos do assunto quando advertem das intenções, ainda que veladas, da ideologia neoliberal, que pode utilizar da descentralização via municipalização para desconstrução, desregulamentação e descompromisso do Estado para com a educação pública fundamental. Tal discurso ideológico, levado às últimas consequências, tem um "inequívoco sentido privatizante" 219 .

As questões de ordem ideológica desembocam-se no grande desafio que consiste na superação da democracia puramente formal, expressa no discurso legal, para implantação efetiva da democracia substancial, referente não aos meios (função da democracia formal), mas aos fins que são alcançados de fato na realidade social. Cabe, porém, perguntar se os que detêm o poder de decisão, estão realmente empenhados na solução desse desafio, já que a história tem demonstrado o contrário, pelo descompasso, talvez intencional entre o discurso normativo e a real prática pedagógica diuturna das escolas públicas.

A lógica do interesse privado geralmente não coincide com o bem coletivo. Entendem os estudiosos, que no momento, não há solução pronta para tal problema. Se são verdadeiras as críticas feitas ao socialismo real (não o sonhado e teorizado pelos socialistas ) e ao capitalismo real, é preciso reinventar a política, reestruturar o poder em todos os seus níveis, construir as soluções adequadas. Se o capitalismo é o estado de injustiça e o socialismo, o da não liberdade, nas sábias palavras de Norberto Bobbio ${ }^{220}$, é preciso agora descobrir a maneira de conciliar a igualdade de oportunidades com a liberdade, ou seja, unir o socialismo com a democracia, o que para muitos é uma tarefa impossível.

\footnotetext{
${ }^{219}$ OLIVEIRA, Romualdo Portela. In: DALIDA, Andrade Oliveira (org). Gestão democrática da educação. Petrópolis: Vozes, 1997. p. 179.

${ }^{220}$ BOBBIO, Norberto. In: ARANHA, Maria Lúcia de Arruda, MARTINS, Maria Helena Pires. Filosofando. 2. ed. São Paulo: Moderna, 1993. p. 270.
} 
A saída, para muitos, estaria na economia mista, reunindo empresas estatais e particulares, a fim de conjugar a economia de planejamento com a economia de mercado, pois entre os extremos do laissezfaire e do estatismo, devem existir fórmulas, as mais variadas e inteligentes de controle da economia, que têm relação direta com o funcionamento das áreas sociais. Evidenciou-se que, para o funcionamento adequado da economia, são necessários mecanismos políticos que garantem a prevalência dos valores coletivos sobre os individuais.

Ressaltou-se que municipalizar significa trazer os problemas para mais perto do povo a fim de que este participe de suas soluções, o que implica numa autogestão municipalizada, com todas as cautelas, precauções, recomendações e condições descritas anteriormente. Afirmou-se, também, que o povo mora no Município e nele tem sua escola, seu lar, sua profissão, sua propriedade, suas instituições, seus interesses e aspirações. A União e o Estado se colocam mais no plano ideológico das abstrações jurídico - constitucionais, sendo o Município a única realidade política concreta, capaz de assegurar a efetiva participação de seus munícipes e de suprir em primeira mão, suas aspirações e necessidades. Em contrapartida, é justo e necessário que ele receba os devidos apoios e recursos e atue de forma integrada com o Estado e a União, a fim de assegurar o desenvolvimento político, social e econômico.

Entendeu-se até, defendendo uma posição ousada e inovadora neste país, que os Estados deveriam ser eliminados, pelo poder constituinte original, enxugando profundamente a organização políticoadministrativa da federação, diminuindo os gastos para manter uma estrutura burocrática gigante, carreando mais recursos financeiros, humanos e materiais para os Municípios. Uma reforma constitucional deste porte, aos olhos de muitos cientistas políticos pode até parecer utopia. Se assim entenderem, espera-se que essa utopia seja sinônimo de "descrição ou representação de qualquer lugar ou situação ideais onde vigorem normas e/ou instituições políticas altamente aperfeiçoadas" e não um "projeto irrealizável". 221

Essa proposta, para ser viável, exige obviamente uma série de medidas complementares a cargo do legislador constitucional, revestido de poder constituinte derivado e do legislador ordinário que atuando de forma intercomplementar, proponham as reformas na organização dos

\footnotetext{
${ }^{221}$ FERREIRA, Aurélio Buarque de Holanda. Novo dicionário da língua portuguesa. 2. ed. Rio de Janeiro: Nova Fronteira, 1986. p. 1745.
} 
poderes, na tributação e no orçamento, na ordem econômica, financeira e social, dentro dos parâmetros da justiça distributiva e social.

A própria autonomia assegurada constitucionalmente aos Municípios (art. 18), é bastante limitada, uma vez que o Município não tem Poder Judiciário e o seu poder legiferante é subsidiário em muitos assuntos diante da supremacia e hierarquia das leis. Alguns estudiosos questionam também a sua qualidade de ente federativo autônomo por lhe faltar representatividade no Senado Federal.

Em que pesem todas essas discussões, uma induvidosa conclusão se apresenta lúcida e transparente: o Município com seu Poder Público Municipal e sua Administração Pública, existe mais para a população que o próprio Estado e a União.

Todas as possíveis soluções descritas a seguir, dependem da vontade política de nossos governantes de elegerem a educação pública como prioridade social e política, bem como concebê-la como investimento na qualidade de vida de seu povo e de suas instituições democráticas.

Ocorrendo a passagem das intenções políticas do plano teórico e subjetivo para o plano operacional, este exige, dentre outras soluções já aventadas, as seguintes:

a) reelaboração da experiência jurídico-pedagógica pelo próprio Município, necessário para subsidiar o projeto pedagógico de suas escolas afinado com suas características específicas e com a base nacional comum e que seja capaz de responder a problemas concretos referentes à estrutura e ao funcionamento de suas escolas;

b) investimento significativo e imediato na construção e consolidação de um amplo sistema nacional de educação, integrado com os sistemas estaduais e municipais de educação, possível somente se a educação for realmente considerada como prioridade social e política;

c) aumento significativo e imediato do percentual do PIB destinado à educação, como consequência de sua priorização, acompanhado de maiores encargos e responsabilidades conferidas legalmente aos Municípios. Considerando-se os números disponíveis, referentes às últimas décadas, penso que se deveria fazer um esforço de dobrar o índice fixando um valor em torno de 8,0 \% do PIB, taxa que nos aproximaria dos países que mais investem em educação, o que sugere tratar-se de uma meta viável;

d) composição de seus próprios sistemas de ensino quando se tratar de Municípios com significativa demanda escolar e adequada receita 
orçamentária ( geralmente Municípios maiores ), sustentado pelos recursos vinculados constitucionalmente nas três esferas de governo, gerido democraticamente com a participação dos vários segmentos sociais organizados. A possibilidade da construção de um sistema único de educação básica (Parágrafo único do art. 11 da LDB) recomendada pela Associação dos Professores do Ensino Oficial do Estado de São Paulo (APEOESP), interrompendo o processo de municipalização no Estado de São Paulo, a nosso ver, não deve constituir medida única e uniformizadora para uma realidade tão heterogênea. Trata-se de uma alternativa legal, recomendável para os Municípios que apresentam escassez de recursos financeiros e significativa demanda escolar (geralmente Municípios menores). A análise contábil de todas as modalidades de financiamento para o ensino fundamental representa o indicador mais seguro para um a decisão desta natureza;

e) colaboração da universidade para o desenvolvimento de projetos experimentais de municipalização de ensino, envolvendo a qualificação de recursos humanos, assistência técnica para uma gestão sintonizada de Reitores das Universidades Brasileiras - CRUB; ${ }^{222}$

f) concepção de uma política municipalizada de educação que situe o Município como parte constituinte de um sistema maior, articulando-o nacionalmente e no âmbito estadual, como verdadeiro parceiro compromissado com a qualidade da educação pública, possibilitando o atendimento das prioridades educacionais definidas no Plano Nacional de Educação e articuladas com os planos estaduais e municipais de educação;

g) transformação das escolas municipalizadas em unidades de despesas, com autonomia orçamentária, eliminando ou diminuindo os entraves burocráticos, agilizando os processos de prestação de contas, racionalizando as despesas, adequando-as às reais necessidades das unidades escolares dos sistemas de ensino municipais;

h) avaliação dos resultados, através da instituição de mecanismos internos e externos de avaliação, com responsabilização efetiva pelo cumprimento da proposta pedagógica;

i) implementação, por parte do Poder Público Municipal, do orçamento participativo, instrumento de consulta popular, visando eleger as prioridades que constarão do orçamento municipal, dentro de diretrizes

${ }^{222}$ CONSELHO de Reitores das Universidades Brasileiras - CRUB. Subsídios para a elaboração da nova LDB e D.N.E. Porto Alegre, 9. dez., 1987. p. 5. 
orçamentárias do governo municipal, melhorando a qualidade da representação popular, eliminando alguns vícios do sistema democrático de representação indireta, que nem sempre respeita os reais interesses e necessidades da coletividade;

j) implantação de escolas de tempo integral, com atividades educativas (esporte, cultura, lazer) e assistenciais a serviço da aprendizagem, numa perspectiva interdisciplinar, como exigência de uma educação integral para os Municípios com relevantes recursos financeiros, evitando-se com essa medida, a aplicação de recursos em ações e projetos de fraca repercussão na qualidade do processo de aprendizagem. Tal proposta, conta com o respaldo legal da Lei Federal n. 9394/96 (LDB) em seus artigos. $34, \S 2^{\circ}$ e $87, \S 5^{\circ}$, que a assegura de forma progressiva, a critério dos sistemas de ensino, que na prática ficará, lamentavelmente, na dependência da vontade política dos seus responsáveis.

Em suma, o estado atual do ordenamento jurídico-educacional brasileiro, mesmo sem contar com a real possibilidade de complementá-lo e aperfeiçoá-lo, contém elementos suficientes para a operacionalização do processo de municipalização do ensino fundamental regular, dentro dos parâmetros propostos.

O estudo e análise dos pressupostos, das condições e das vantagens da municipalização do ensino regular, demonstraram a oportunidade, conveniência, necessidade e a viabilidade da proposta.

Do exposto, resta ainda, a efetiva atuação dos homens que conduzirão esse processo, componente essencial para o sucesso de qualquer empreendimento, em especial na área educacional, que geralmente foge ao controle normativo, técnico e pedagógico. Desse elemento imprevisível, espera-se, apenas, um posicionamento ideológico, fundamentado numa ética antropológica de solidariedade, de compromisso sincero com a qualidade da educação pública e imbuído de uma vontade política de realizála.

Só uma luta incessante pelo fortalecimento e autonomia do $\mathrm{Mu}$ nicípio será capaz de fortalecer e consolidar a República Federativa do Brasil, formada constitucionalmente pela união indissolúvel dos Estados e dos Municípios, pois "não é possível a nenhum povo conservar-se politicamente forte sem uma forte organização municipal". ${ }^{223}$

223 SANTI ROMANO, In: PINASSI, Ayton. Direito Municipalista Constitucional. Campinas: Conan, 1995. p.11. 


\section{REFERÊNCIAS BIBLIOGRÁFICAS}

GUSMÃO, Paulo Dourado de. Introdução ao estudo do Direito. 39. ed. Rio de Janeiro: Forense, 2007.

DI DIO, Roberto Teodoro. Contribuição à Sistematização do Direito Educacional. Taubaté: Imprensa Universitária/Universidade de Taubaté, 1982.

SILVA, Pedro Sancho da. Sistematização do Direito Educacional. Revista do Direito Educacional. Rio de Janeiro, Ano 9, n.46, set./out., 1997.

CERCO a Prefeitos Corruptos. Jornal da Tarde (Editorial), São Paulo, 14 ago. 1998.

CARVAlHO, José Raimundo. A Constituição e o Plano Nacional de Educação. In: Conselho de Reitores das Universidades Brasileiras. Brasília, 1988.

BRASIL. MEC - Secretário do Ensino Básico, 1998.

MÁXIMO, Antônio Carlos. A municipalização do ensino. Brasília: Ministério da Educação, INEP, Ano 2, no 9, dez.1987.

FORMOSINHO, João. A Regionalização do Sistema De Ensino. In: Cadernos Municipais. Braga. n.38-39, dez. 1986.

OLIVEIRA, Romualdo Portela. In: DALIDA, Andrade Oliveira (org). Gestão democrática da educação. Petrópolis: Vozes, 1997.

BOBBIO, Norberto. In: ARANHA, Maria Lúcia de Arruda, MARTINS, Maria Helena Pires. Filosofando. 2.ed. São Paulo: Moderna, 1993.

FERREIRA, Aurélio Buarque de Holanda. Novo dicionário da língua portuguesa. 2. ed. Rio de Janeiro: Nova Fronteira, 1986.

CONSELHO de Reitores das Universidades Brasileiras - CRUB. Subsídios para a elaboração da nova LDB e D.N.E. Porto Alegre, 9. dez., 1987.

SANTI ROMANO, In: PINASSI, Ayton. Direito municipalista constitucional Campinas: Conan, 1995. 
